Pure Appl. Chem., Vol. 83, No. 5, pp. 1159-1162, 2011.

doi:10.1351/PAC-REC-09-01-22

(C) 2011 IUPAC, Publication date (Web): 8 April 2011

\title{
IUPAC-IUGS common definition and convention on the use of the year as a derived unit of time (IUPAC Recommendations 2011) ${ }^{\star, \star *}$
}

\author{
Norman E. Holden 1,3 , Mauro L. Bonardi 1,4 , Paul De Bièvre ${ }^{1,5}$, \\ Paul R. Renne $2,6,7$, and Igor M. Villa $2,8,9, \ddagger$ \\ ${ }^{1}$ International Union of Pure and Applied Chemistry; ${ }^{2}$ International Union of \\ Geological Sciences; ${ }^{3}$ National Nuclear Data Center, Brookhaven National \\ Laboratory, Upton, NY 11973, USA; ${ }^{4}$ LASA, Università degli Studi di Milano and \\ INFN, I-20090 Segrate, Italy; ${ }^{5}$ Consultant on Metrology in Chemistry, Duineneind 9, \\ B-2460 Kasterlee, Belgium; ${ }^{6}$ Berkeley Geochronology Center, 2455 Ridge Road, \\ Berkeley, CA 94720, USA; ${ }^{7}$ Department of Earth and Planetary Science, University \\ of California, Berkeley, CA 94720, USA; ${ }^{8}$ Institut für Geologie, Universität Bern, \\ CH-3012 Bern, Switzerland; ${ }^{9}$ Università di Milano Bicocca, I-20126 Milano, Italy
}

\begin{abstract}
The units of time (both absolute time and duration) most practical to use when dealing with very long times, for example, in nuclear chemistry and earth and planetary sciences, are multiples of the year, or annus (a). Its proposed definition in terms of the SI base unit for time, the second (s), for the epoch 2000.0 is $1 \mathrm{a}=3.1556925445 \times 10^{7} \mathrm{~s}$. Adoption of this definition, and abandonment of the use of distinct units for time differences, will bring the earth and planetary sciences into compliance with quantity calculus for SI and non-SI units of time.
\end{abstract}

Keywords: annus; decay constants; geochronology; IUPAC Analytical Chemistry Division; IUPAC Inorganic Chemistry Division; SI units; units of time.

\section{INTRODUCTION}

The International Union of Pure and Applied Chemistry, IUPAC, and the International Union of Geological Sciences, IUGS, set up a task group in October 2006 with the goal of updating the recommendations on radioactive decay constants (and half-lives) for geochronological use, last formalized in 1976.

In the course of the initial assessment, it was noticed that use of units for time in the geological literature is inconsistent both internally and with respect to SI (Le Système international d'unités). A source of inconsistency is the perceived contrast between "absolute time", or "age", i.e., the time difference between "now" and an event in the past, and the time difference between two events in the past. This issue is addressed immediately, as it requires neither new experiments nor extensive literature evaluations but only judgment and adherence to SI rules.

\footnotetext{
*Sponsoring bodies: IUPAC Analytical Chemistry Division; IUPAC Inorganic Chemistry Division; International Union of Geological Sciences; Joint IUPAC-IUGS Task Group on Isotope Data in Geosciences: see more details on page 1161.

** This paper will also appear in the official IUGS journal, Episodes.

‡Corresponding author: E-mail: igor@geo.unibe.ch
} 


\section{SI AND NON-SI UNITS FOR TIME}

The SI unit of time, the second (s), is impractical for expressing very long time intervals both for earth scientists and nuclear physicists alike. In such cases, other units are accepted for use with the SI. For geological and astronomical applications and for use with long-lived radioactive nuclides the year, or annus (symbol, a), is used [1-4].

The definition of the year in terms of the SI base unit, the second, is no trivial matter, as the year is not commensurable with the day, and is not a constant. There are several possible definitions available for the year, such as Julian, Mayan, Gregorian [1], Tropical (or Solar) and Sidereal. It is desirable that the chosen definition be stable with respect to long-term mismatch, i.e., it should contain a term accounting for variations of the year over time. None of the existing definitions of the annus fully embodies this fundamental principle. Definitions of the annus that are based on an intermediate relationship via the day, such as the Julian and Gregorian year, bear an inherent, pre-programmed obsolescence because of the variability of Earth's orbital movement.

Prior to the introduction of the atomic standard to define the second in 1967 (and the subsequent refinement in 1997, see ref. [5]), the SI definition of the second derived in terms of a fraction of a tropical year, for the epoch 1900.0, was "the second is the fraction 1/31 556925.9747 of the tropical year for 1900 January 1 at 12 hours ephemeris time [6]".

In view of the necessity to define units for time in such a way that they can be considered as constant for practical purposes, it is here recommended to define the year directly on the basis of the SI unit, the second. The Task Group proposes the annus as a defined multiple of the second that minimizes time-dependent inaccuracy. The present recommendation effectively reverses the definition used by [6] in favor of a more precise and up-to-date definition of the second. Taking into account the non-relativistic estimate of astronomical decrease by $0.530 \mathrm{~s}$ per century [1], for the epoch 2000.0 the year amounts to $31556925.445 \mathrm{~s}$.

The unit a can be supplemented with prefixes $\mathrm{k}\left(\times 10^{3}\right)$, $\mathrm{M}\left(\times 10^{6}\right)$, and $\mathrm{G}\left(\times 10^{9}\right)$, without a fullstop between the prefix and the unit, viz. ka, Ma, and Ga to designate thousand, million, and billion (USA usage) years, respectively. These derived units are already in widespread use in earth and planetary science literature, though as noted above they lack precise definition. The departure lies in the use of different units (e.g., m.y., from the American Engineering Society) for ages and time differences, such that the interval between 90 and $100 \mathrm{Ma}$, for example, is sometimes designated as $10 \mathrm{~m} . \mathrm{y}$. Instead, following quantity calculus [4], units must follow algebraic rules such as the distributive law: $100 \mathrm{Ma}-$ $90 \mathrm{Ma}=(100-90) \mathrm{Ma}=10 \mathrm{Ma}$, and so on. Similarly, half-lives should be expressed in ka, Ma, or Ga, and decay constants and rates of geological processes in $\mathrm{ka}^{-1}, \mathrm{Ma}^{-1}$, or $\mathrm{Ga}^{-1}$. The definition of the second, and of the year based on the second, is that of a duration, or time interval. All time measurements are performed with respect to some reference datum, and the semantic distinction between age and duration depends solely on the choice of datum. Therefore, both should have the same units, and specification of the reference datum should be embodied in the context rather than in a distinct unit. In other words, in order to express an age, or absolute time, the same unit must be used as for time duration, with the optional addition of qualifiers such as "ago" or "before present" if a disambiguation is required. In such cases, it is implicit that the reference datum is the time of measurement, or a conventional datum such as 1950.0 or 2000.0. Analogies on the use of absolute and relative SI units are useful; for example, it is rarely denied that the depth difference between 100 and $200 \mathrm{~m}$ below ground level in a borehole is $100 \mathrm{~m}$.

It is therefore recommended that geoscientists no longer express time durations in distinct ad hoc units such as k.y., M.y., or G.y. The goal is achieving compliance with the international standard by expressing time durations as a, ka, Ma, Ga. 


\section{MEMBERSHIP OF SPONSORING BODIES}

Membership of the IUPAC Analytical Chemistry Division Committee for the period 2008-2009 was as follows:

President: A. Fajgelj (Slovenia); Vice President: W. Lund (Norway); Secretary: D. B. Hibbert (Australia); Past President: R. Lobinski (France); Titular Members: M. F. Camões (Portugal); Z. Chai (China); P. De Bièvre (Belgium); J. Labuda (Slovakia); Z. Mester (Canada); S. Motomizu (Japan); Associate Members: P. De Zorzi (Italy); A. Felinger (Hungary); M. Jarosz (Poland); D. E. Knox (USA); P. Minkkinen (Finland); J. M. M. Pingarrón (Spain); National Representatives: S. K. Aggarwal (India); R. Apak (Turkey); M. S. Iqbal (Pakistan); H. Kim (Korea); T. A. Maryutina (Russia); R. M. Smith (UK); N. Trendafilova (Bulgaria); Provisional Member: N. Torto (Botswana).

Membership of the IUPAC Inorganic Chemistry Division Committee for the period 2008-2009 was as follows:

President: K. Tatsumi (Japan); Vice President: R. D. Loss (Australia); Secretary: L. V. Interrante (USA); Past President: A. R. West (UK); Titular Members: T. B. Coplen (USA); T. Ding (China/Beijing); J. García-Martínez (Spain); M. Leskelä (Finland); L. A. Oro (Spain); J. Reedijk (Netherlands); M. P. Suh (Korea); Associate Members: A. V. Chadwick (UK); M. Drábik (Slovakia); N. E. Holden (USA); S. Mathur (Germany); K. Sakai (Japan); J. Takats (Canada); National Representatives: T. V. Basova (Russia); A. Bologna Alles (Uruguay); R. Gonfiantini (Italy); P. Karen (Norway); L.-K. Liu (China/Taipei); L. R. Öhrström (Sweden).

Membership of the IUGS Executive Committee is as follows:

President: A. C. Riccardi (Argentina); Secretary General: P. Bobrowsky (Canada); Treasurer: W. Cavazza (Italy); Past President: H. Zhang (China); Vice Presidents: J. Charvet (France), O. Gerel (Mongolia); Councillors: E. Errami (Morocco), C. Simpson (Australia), W. Hill (USA), S. K. Tandon (India).

Membership of the Joint IUPAC-IUGS Task Group on Isotope Data in Geosciences for the period 2006-2009 was as follows: M. L. Bonardi, P. De Bièvre, A. Fajgelj (IUPAC, International Atomic Energy Agency, Vienna, Austria), N. E. Holden, D. Y. Liu (IUGS, Beijing Shrimp Laboratory, Beijing, China), P. R. Renne, I. M. Villa.

\section{ACKNOWLEDGMENTS}

Helpful discussions with Prof. Ian M. Mills and comments by N. Christie-Blick, L. E. Edwards, F. Oberli, A. J. Thor, J. Zabicky, 13 unnamed referees, and the editorial input by J. W. Lorimer are gratefully acknowledged.

\section{REFERENCES}

1. IUPAC. Quantities, Units and Symbols in Physical Chemistry, $3^{\text {rd }}$ ed. (the "Green Book"). Prepared for publication by E. R. Cohen, T. Cvitaš, J. G. Frey, B. Holmström, K. Kuchitsu, R. Marquardt, I. Mills, F. Pavese, M. Quack, J. Stohner, H. L. Strauss, M. Takami, A. J. Thor, p. 137, RSC Publishing, Cambridge, UK (2007).

2. IUPAP. Symbols, Units and Nomenclature and Fundamental Constants in Physics, $<\mathrm{http}: / /$ metrology.wordpress.com/measurement-process-index/iupap-red-book/>.

3. Recommendations concerning Units. Reprinted from the "IAU Style Manual" by G. A. Wilkinson, Comm. 5, in IAU Transactions XXB (1987). <http://www.iau.org/science/publications/proceedings_rules/units/> 
4. A. Thompson, B. N. Taylor. Special Publication 811: Guide for the Use of the International System of Units (SI), National Institute of Standards and Technology (NIST), Gaithersburg, MD, USA (2008).

5. BIPM. Le Système international d'unités - The International System of Units SI, $8^{\text {th }}$ ed., Bureau International des Poids et Mesures, Geneva (2006). <http://www.bipm.fr/fr/si/si_brochure/>

6. The $11^{\text {th }}$ General Conference on Weights and Measures (GGPM), Resolution 9; CR 86 (1960).

Republication or reproduction of this report or its storage and/or dissemination by electronic means is permitted without the need for formal IUPAC permission on condition that an acknowledgment, with full reference to the source, along with use of the copyright symbol $\odot$, the name IUPAC, and the year of publication, are prominently visible. Publication of a translation into another language is subject to the additional condition of prior approval from the relevant IUPAC National Adhering Organization. 